\section{The bacteria with a difference}

\section{D.B. Nedwell}

Archaebacteria. The Bacteria: A Treatise on Structure and Function, Vol. VIII. Edited by Carl R. Woese and Ralph S. Wolfe. Academic: 1985. Pp.582. \$85, $£ 85$.

THE aim of this series of books, of which this volume is the eighth, is a comprehensive review of the structure and function of bacteria. Previous volumes have been concerned with structure, metabolism, biosynthesis, etc., but this latest volume is rather different in not being orientated towards a topic but dealing in depth with a specific group of microorganisms.

Archaebacteria are the group considered, despite accumulating evidence that they are quite distinct from most prokaryotic bacteria. The editors' introduction emphasizes this point, and that the degree of difference between prokaryotic bacteria and archaebacteria justifies their placement in distinct kingdoms. The inclusion of a volume on the archaebacteria in a series on bacteria is, therefore, a contradiction, but nonetheless justified as they have in the past been considered as prokaryotic bacteria, which they superficially resemble. Comparison of information in this volume with that on prokaryotes in preceding volumes indicates the basis upon which this fundamental division has been established.

The book is divided into three sections: biochemical diversity and ecology; RNA translation apparatus; and general molecular characteristics. Chapters in the first section deal specifically with each of the major groups of archaebacteria: the methanogens and extreme halophiles, together with the thermoacidophiles (sulphur-dependent archaebacteria). Each chapter succinctly reviews the taxonomy, ecology and biochemistry of the group, as far as it is known, and an interesting fourth chapter in this section deals with the geochemical evidence of archaebacterial evolution from the sedimentary record, including abundance and distribution of archaebacterial biomarkers.

The second section has four chapters dealing with archaebacterial ribosomes, nucleic acids and elongation factors: while in the third section, five chapters cover, amongst other topics, cell envelopes, lipids, antibiotic sensitivity and genome structure. This last section tends to be rather a catch-all without the cohesion found between chapters in the first two sections, but this is probably inevitable given the large gaps in current knowledge of the group.

The book is well produced. The standard of writing is uniformly lucid and com- prehensive, and the text is well illustrated with photographic plates at relevant points. The high standard set by the preceding volumes in this series has been maintained. It pulls together and presents the overall evidence for the distinct nature of archaebacteria, which should be extremely useful for teachers having to adjust their undergraduate lectures to reflect the many recent developments in the knowledge about these organisms. At its price I doubt whether it will find many private purchasers, but it is predominantly a reference text which, in institutional libraries, will be particularly useful at the postgraduate level.

D.B. Nedwell is a Lecturer in the Department of Biology, University of Essex, Colchester $\mathrm{CO} 4$ $3 S Q$, UK

\section{Living in the past}

\section{Paul G. Bahn}

On the Track of Ice Age Mammals. By Antony J. Sutcliffe. British Museum (Natural History):1985. Pp.224. £12.95. To be published in the United States later this year by Harvard University Press, \$25.

ANTONy Sutcliffe has produced a book which is, presumably, aimed at the kind of interested laymen who visit the Natural History Museum in London. Scholars in the several disciplines on which he draws will merely pick up some new information here and there, but the general public will find a well-produced guide to many aspects of the Ice Age - easy to read, wide-ranging and profusely illustrated (the five colour reconstructions of fauna in landscapes are particularly fine).

The author stresses that he has not written the book as a comprehensive treatise on Ice Age fauna. Instead he has wisely concentrated on a selection of subjects, sites and parts of the world. Inevitably, perhaps, there is an imbalance caused by emphasis on areas with which Sutcliffe himself is most familiar. Thus readers are presented with rather more information on British quaternary deposits and terraces than they might welcome; the East African evidence and the work of the Leakeys is covered in far more detail than South African material; and while early man looms large in the African chapter, he is barely mentioned in chapters on other parts of the world. This is regrettable since the thorny question of when man entered the New World and Australia has much relevance to the problem of animal extinctions, covered in the final chapter.

The chapter on dating explains some methods and their applications with great clarity, but one wonders why terms such as "isotope" and "amino acid racemization" are left unexplained. Part of the author's task was to show how a specialist in one field needs to draw on researches in others. He has generally succeeded in this, but the difficulty of coping with such a wide range of topics shows through at times, especially in the chapter on palaeolithic art which contains several elementary mistakes: there is no salmon engraving in the floor of Bédeilhac cave (it is in Niaux); Kesslerloch cave is in Switzerland; and there was never a continuous barrier of ice from the Atlantic to the Mediterranean along the Pyrenees Spain was never cut off completely from France.

The fact remains that it is notoriously difficult to write a serious but accessible account of any part of science. Future visitors to the Natural History Museum, and like-minded people elsewhere, should be grateful to the author for providing them with such an elegant and informative book.

Paul G. Bahn is currently a J. Paul Getty Postdoctoral Fellow in the History of Art and the Humanities, and can be contacted clo the School of Archaeology, University of Liverpool, PO Box 147, Liverpool L69 $3 B X$, UK
Frozen find: the carcass of a 6-7-month-old woolly mammoth, discovered near the River Kirgilyakh, Siberia, in 1977. The animal died some 40,000 years ago, and was $115 \mathrm{~cm}$ long, $104 \mathrm{~cm}$ high and had a trunk $57 \mathrm{~cm}$ in length. In life it had a hairy coat, some of which is still visible around the feet. (Reproduced from On the Track of Ice Age Mammals, courtesy USSR Academy of Sciences.) 